\title{
New Oscillation Criteria for Second-Order Neutral Delay Differential Equations with Positive and Negative Coefficients
}

\author{
Yuzhen Bai and Lihua Liu \\ School of Mathematical Sciences, Qufu Normal University, Qufu 273165, China \\ Correspondence should be addressed to Yuzhen Bai, baiyu99@126.com \\ Received 23 November 2009; Revised 8 May 2010; Accepted 11 June 2010 \\ Academic Editor: Ağacık Zafer
}

Copyright (C) 2010 Y. Bai and L. Liu. This is an open access article distributed under the Creative Commons Attribution License, which permits unrestricted use, distribution, and reproduction in any medium, provided the original work is properly cited.

We establish the oscillation and asymptotic criteria for the second-order neutral delay differential equations with positive and negative coefficients having the forms $\left[x(t)+\sum_{i \in R} c_{i}(t) x\left(\alpha_{i}(t)\right)\right]^{\prime \prime}+$ $r(t)\left[x(t)+\sum_{i \in R} c_{i}(t) x\left(\alpha_{i}(t)\right)\right]^{\prime}+\sum_{i \in P} p_{i}(t) x\left(\beta_{i}(t)\right)-\sum_{i \in Q} q_{i}(t) x\left(\gamma_{i}(t)\right)=0$ and $[x(t)+$ $\left.\sum_{i \in R} c_{i}(t) x\left(\alpha_{i}(t)\right)\right]^{\prime \prime}+r(t)\left[x(t)+\sum_{i \in R} c_{i}(t) x\left(\alpha_{i}(t)\right)\right]^{\prime}+\sum_{i \in P} p_{i}(t) x\left(\beta_{i}(t)\right)-\sum_{i \in Q} q_{i}(t) x\left(\gamma_{i}(t)\right)=f(t)$. The obtained new oscillation criteria extend and improve the recent results given in the paperof $B$. Karpuz et al. (2009).

\section{Introduction}

In this paper, we consider the oscillation of all solutions of the second-order neutral delay differential equations with positive and negative coefficients having the forms

$$
\begin{gathered}
{\left[x(t)+\sum_{i \in R} c_{i}(t) x\left(\alpha_{i}(t)\right)\right]^{\prime \prime}+r(t)\left[x(t)+\sum_{i \in R} c_{i}(t) x\left(\alpha_{i}(t)\right)\right]^{\prime}+\sum_{i \in P} p_{i}(t) x\left(\beta_{i}(t)\right)-\sum_{i \in Q} q_{i}(t) x\left(\gamma_{i}(t)\right)=0} \\
{\left[x(t)+\sum_{i \in R} c_{i}(t) x\left(\alpha_{i}(t)\right)\right]^{\prime \prime}+r(t)\left[x(t)+\sum_{i \in R} c_{i}(t) x\left(\alpha_{i}(t)\right)\right]^{\prime}+\sum_{i \in P} p_{i}(t) x\left(\beta_{i}(t)\right)-\sum_{i \in Q} q_{i}(t) x\left(\gamma_{i}(t)\right)=f(t) .}
\end{gathered}
$$

We introduce the following class of functions $D\left(\left[t_{0}, \infty\right)\right)$ equipped with the functions satisfying the following properties:

$\left(P_{1}\right) f \in C^{1}\left(\left[t_{0}, \infty\right), \mathbb{R}\right)$ is strictly increasing and $\lim _{t \rightarrow \infty} f(t)=\infty$ holds, 
$\left(P_{1}\right) f(t) \leq t$ holds for all $t \geq t_{0}$.

In this paper, we make the following assumptions:

$\left(H_{1}\right) R, P, Q$ are bounded starting segments of positive integers; that is,

$$
R=\left\{1,2, \ldots, R_{0}\right\}, \quad P=\left\{1,2, \ldots, P_{0}\right\}, \quad Q=\left\{1,2, \ldots, Q_{0}\right\}, \quad R_{0}, P_{0}, Q_{0} \in \mathbb{N} ;
$$

$\left(H_{2}\right) c_{i} \in C\left(\left[t_{0}, \infty\right), \mathbb{R}^{+}\right)$for all $i \in R, p_{i} \in C\left(\left[t_{0}, \infty\right), \mathbb{R}^{+}\right)$for all $i \in P$, and $q_{i} \in$ $C\left(\left[t_{0}, \infty\right), \mathbb{R}^{+}\right)$for all $i \in Q$;

$\left(H_{3}\right) \alpha_{i} \in D\left(\left[t_{0}, \infty\right)\right)$ with $\lim _{\inf _{t \rightarrow \infty}} \alpha_{i}^{\prime}(t)>0$ for all $i \in \mathrm{R}, \beta_{i} \in D\left(\left[t_{0}, \infty\right)\right)$ for all $i \in P$, and $\gamma_{i} \in D\left(\left[t_{0}, \infty\right)\right)$ for all $i \in Q$;

$\left(H_{4}\right) r \in C^{1}\left(\left[t_{0}, \infty\right), \mathbb{R}^{+}\right)$, and $r^{\prime}(t) \leq 0$;

$\left(H_{5}\right) \quad f \in C\left(\left[t_{0}, \infty\right), \mathbb{R}\right)$ and that there exists a function $F \in C^{2}\left(\left[t_{0}, \infty\right), \mathbb{R}\right)$ which satisfies $F^{\prime \prime}=f$ and $\lim _{t \rightarrow \infty} F(t)=0$.

In order to establish our main results, we will assume that there exists a mapping $\psi: Q \rightarrow P$ satisfying the following conditions:

$\left(A_{1}\right) \gamma_{i}(t) \geq \beta_{\psi(i)}(t)$ for all $t \geq t_{0}$ and $i \in Q$;

$\left(A_{2}\right) h_{i} \in C\left(\left[t_{0}, \infty\right), \mathbb{R}^{+}\right)$for all $i \in P$, where

$$
h_{i}(t):= \begin{cases}p_{i}(t)-\sum_{j \in Q, \psi(j)=i} \rho_{j}^{\prime}(t) q_{j}\left(\rho_{j}(t)\right), & i \in \psi(Q), \\ p_{i}(t), & i \notin \psi(Q),\end{cases}
$$

and $\rho_{i}(t):=\gamma_{i}^{-1}\left(\beta_{\psi(i)}(t)\right)$ for all $i \in Q$ and $t \geq t_{0} ;$

$\left(A_{3}\right)$ there exists $i_{0} \in P$ such that $\lim \inf _{t \rightarrow \infty} h_{i_{0}}(t)>0$ and $\lim \sup _{t \rightarrow \infty} \beta_{i_{0}}^{\prime}(t)<\infty$.

A function $x$ is called a solution of (1.1) (or (1.2)) provided that $x$ satisfies (1.1) (or (1.2)) identically on $\left[t_{0}, \infty\right), x+\sum_{i \in R} c_{i}(t) x \circ \alpha_{i} \in C^{2}\left(\left[t_{0}, \infty\right), \mathbb{R}\right)$ and $x \in C\left(\left[t_{-1}, \infty\right), \mathbb{R}\right)$, where $t_{-1}:=\min \{\alpha, \beta, \gamma\}, \alpha:=\min \left\{\alpha_{i}\left(t_{0}\right): i \in R\right\}, \beta:=\min \left\{\beta_{i}\left(t_{0}\right): i \in P\right\}$, and $\gamma:=\min \left\{\gamma_{i}\left(t_{0}\right):\right.$ $i \in Q\}$. We restrict our attention only to the nontrivial solution $x$, that is, to the solution $x$ such that $\sup \left\{|x(t)|: t \geq t_{1}\right\}>0$ for all $t_{1} \geq t_{0}$. A nontrivial solution of (1.1) (or (1.2)) is called oscillatory if it has arbitrary large zeros, otherwise, it is called nonoscillatory.

The oscillation and nonoscillation of solutions of second-order neutral delay differential equations have been studied by many authors; see [1-10]. However, to the best of our knowledge,there seem to be few oscillation results for (1.1) and (1.2).

Recently,Manojlović et al. [4] andWeng and Sun [10] have studied oscillation and asymptotic behavior of all solutions of the following equations:

$$
\begin{gathered}
{\left[x(t)+\sum_{i=1}^{l} c_{i}(t) x\left(t-\tau_{i}\right)\right]^{\prime \prime}+\sum_{i=1}^{m} p_{i}(t) x\left(t-\delta_{i}\right)-\sum_{i=1}^{n} q_{i}(t) x\left(t-\sigma_{i}\right)=0, \quad t \geq t_{0},} \\
{\left[x(t)+\sum_{i=1}^{l} c_{i}(t) x\left(t-\tau_{i}\right)\right]^{\prime \prime}+\sum_{i=1}^{m} p_{i}(t) x\left(t-\delta_{i}\right)-\sum_{i=1}^{n} q_{i}(t) x\left(t-\sigma_{i}\right)=f(t), \quad t \geq t_{0},}
\end{gathered}
$$

and several well-known results have been obtained. 
By using weaker conditions than in [4, 10], Karpuz et al. [1] have established oscillation criteria for differential equation

$$
\left[x(t)+\sum_{i \in R} r_{i}(t) x\left(\alpha_{i}(t)\right)\right]^{\prime \prime}+\sum_{i \in P} p_{i}(t) x\left(\beta_{i}(t)\right)-\sum_{i \in Q} q_{i}(t) x\left(\gamma_{i}(t)\right)=f(t) .
$$

In this paper, we shall continue in the direction to study the oscillatory properties of (1.1) and (1.2). We establish new oscillation criteria for (1.1) and (1.2), which extend and improve the corresponding results in $[1,4,10]$. We also give two examples to illustrate our main results.

\section{Main Results}

The following properties of the set $L^{1}\left(\left[t_{0}, \infty\right)\right)$ in [1] are needed for our subsequent discussion.

Property 1. If $f \in L^{1}\left(\left[t_{0}, \infty\right)\right)$ and $f \in C\left(\left[t_{0}, \infty\right), \mathbb{R}^{+}\right)$, then $\lim _{\inf _{t \rightarrow \infty}} f(t)=0$.

Corollary 2.1. Suppose that $f \in L^{1}\left(\left[t_{0}, \infty\right)\right)$ and $\lim _{t \rightarrow \infty} f(t)$ exists; then $\lim _{t \rightarrow \infty} f(t)=0$.

Property 2. If $f \in C\left(\left[t_{0}, \infty\right), \mathbb{R}\right)$ and $f \in L^{1}\left(\left[t_{1}, \infty\right)\right)$, where $t_{1} \geq t_{0}$, then we have $f \in L^{1}\left(\left[t_{0}, \infty\right)\right)$.

Property 3. Let $t_{1}$ be such that $g\left(t_{1}\right) \geq t_{0}$. Suppose $g \in D\left(\left[t_{1}, \infty\right)\right)$ with $\lim \sup _{t \rightarrow \infty} g^{\prime}(t)<\infty$ and $f \in C\left(\left[t_{0}, \infty\right), \mathbb{R}^{+}\right)$. If $f \circ g \in L^{1}\left(\left[t_{1}, \infty\right)\right)$ holds, then $f \in L^{1}\left(\left[t_{0}, \infty\right)\right)$.

Property 4. Let $t_{1}$ be such that $g\left(t_{1}\right) \geq t_{0}$. Suppose $g \in D\left(\left[t_{1}, \infty\right)\right)$ with $\liminf _{t \rightarrow \infty} g^{\prime}(t)>0, f \circ g \in$ $C\left(\left[t_{1}, \infty\right), \mathbb{R}^{+}\right)$, and $f \in C\left(\left[t_{0}, \infty\right), \mathbb{R}^{+}\right)$. If $f \in L^{1}\left(\left[t_{0}, \infty\right)\right)$ holds, then $f \circ g \in L^{1}\left(\left[t_{1}, \infty\right)\right)$ holds.

For simplicity, we denote the set of bounded functions by

$$
B\left(\left[t_{0}, \infty\right)\right):=\left\{f \in C\left(\left[t_{0}, \infty\right), \mathbb{R}\right):\|f\|<\infty\right\},
$$

where

$$
\|f\|:=\sup \left\{|f(t)|, t \geq t_{0}\right\}
$$

For an arbitrary function $\psi: Q \rightarrow P$, which satisfies $\left(A_{1}\right)-\left(A_{3}\right)$, we denote the function $\varphi:\left[t_{0}, \infty\right) \rightarrow \mathbb{R}^{+}$by

$$
\varphi(t):=\sum_{i \in Q} \int_{\rho_{i}(t)}^{t} q_{i}(v) d v, \quad t \geq t_{0} .
$$

In this section, for convenience, we suppose that $q_{i} \equiv 0$ holds for all $i \in Q$ on $\left[t_{-1}, t_{0}\right)$. We start with the following Theorem. 
Theorem 2.2. Assume that $\left(H_{1}\right)-\left(H_{4}\right)$ hold and there exists a mapping $\psi: Q \rightarrow P$ which satisfies $\left(A_{1}\right)-\left(A_{3}\right)$ and that $\sum_{i \in R} c_{i} \in B\left(\left[t_{0}, \infty\right)\right)$. If $\varphi \in L^{1}\left(\left[t_{0}, \infty\right)\right)$, then every solution $x$ of $(1.1)$ is oscillatory.

Proof. Suppose that $x$ is a nonoscillatory solution of (1.1). Without loss of generality, we may assume that $x(t)>0$ for $t \geq t_{0}$. Therefore, we may assume existence of $t_{1} \geq t_{0}$ such that

$$
\int_{t_{1}}^{\infty} \varphi(u) d u<1, \quad \forall t \geq t_{1}, \quad x\left(\alpha_{i}(t)\right)>0, \quad \forall i \in R, \quad x\left(\beta_{i}(t)\right)>0, \quad \forall i \in P .
$$

Now, we set

$$
\begin{gathered}
w(t):=x(t)+\sum_{i \in R} c_{i}(t) x\left(\alpha_{i}(t)\right), \quad t \geq t_{1} \\
z(t, s):=w(t)+\int_{s}^{t} r(u) w(u) d u-\sum_{i \in Q} \int_{s}^{t} \int_{\rho_{i}(u)}^{u} q_{i}(v) x\left(\gamma_{i}(v)\right) d v d u, \quad t \geq s \geq t_{1}
\end{gathered}
$$

By $z^{\prime}(t, s)$, we denote differential of functions with respect to the first component. Considering (2.5), we rewrite (1.1) in the form

$$
w^{\prime \prime}(t)+r(t) w^{\prime}(t)+\sum_{i \in P} p_{i}(t) x\left(\beta_{i}(t)\right)-\sum_{i \in Q} q_{i}(t) x\left(\gamma_{i}(t)\right)=0
$$

on $\left[t_{1}, \infty\right)$. By Leibnitz's rule, $(2.7)$ and $\left(H_{4}\right)$, we have

$$
\begin{aligned}
z^{\prime \prime}\left(t, t_{1}\right) & =w^{\prime \prime}(t)+r^{\prime}(t) w(t)+r(t) w^{\prime}(t)-\sum_{i \in Q} q_{i}(t) x\left(\gamma_{i}(t)\right)+\sum_{i \in Q} \rho_{i}^{\prime}(t) q_{i}\left(\rho_{i}(t)\right) x\left(\beta_{\psi(i)}(t)\right) \\
& \leq w^{\prime \prime}(t)+r(t) w^{\prime}(t)-\sum_{i \in Q} q_{i}(t) x\left(\gamma_{i}(t)\right)+\sum_{i \in Q} \rho_{i}^{\prime}(t) q_{i}\left(\rho_{i}(t)\right) x\left(\beta_{\psi(i)}(t)\right) \\
& =-\sum_{i \in P} p_{i}(t) x\left(\beta_{i}(t)\right)+\sum_{i \in Q} \rho_{i}^{\prime}(t) q_{i}\left(\rho_{i}(t)\right) x\left(\beta_{\psi(i)}(t)\right) \\
& =-\sum_{i \in \psi(Q)} p_{i}(t) x\left(\beta_{i}(t)\right)-\sum_{i \notin \psi(Q)} p_{i}(t) x\left(\beta_{i}(t)\right)+\sum_{i \in \psi(Q)} \sum_{j \in Q, \psi(j)=i} \rho_{j}^{\prime}(t) q_{j}\left(\rho_{j}(t)\right) x\left(\beta_{i}(t)\right) \\
& =-\sum_{i \in \psi(Q)}\left[p_{i}(t)-\sum_{j \in Q, \psi(j)=i} \rho_{j}^{\prime}(t) q_{j}\left(\rho_{j}(t)\right)\right] x\left(\beta_{i}(t)\right)-\sum_{i \notin \psi(Q)} p_{i}(t) x\left(\beta_{i}(t)\right) . \\
& =-\sum_{i \in P} h_{i}(t) x\left(\beta_{i}(t)\right) \leq 0, \quad \forall t \geq t_{1},
\end{aligned}
$$

which implies $z^{\prime}\left(\cdot, t_{1}\right)$ and $z\left(\cdot, t_{1}\right)$ is eventually strictly monotonic on $\left[t_{1}, \infty\right)$. Hence there exists $t_{2} \geq t_{1}$ such that either $z^{\prime}\left(t, t_{1}\right)<0$ or $z^{\prime}\left(t, t_{1}\right)>0$ holds for all $t \geq t_{2}$. 
We consider the following two possible cases:

Case $1\left(z^{\prime}\left(t, t_{1}\right)>0\right.$ for all $\left.t \geq t_{2}\right)$. Integrating (2.8) from $t_{2}$ to $\infty$, we have

$$
\infty>z^{\prime}\left(t_{2}, t_{1}\right) \geq z^{\prime}\left(t_{2}, t_{1}\right)-\lim _{t \rightarrow \infty} z^{\prime}\left(t, t_{1}\right)=-\int_{t_{2}}^{\infty} z^{\prime \prime}\left(u, t_{1}\right) d u=\sum_{i \in P} \int_{t_{2}}^{\infty} h_{i}(u) x\left(\beta_{i}(u)\right) d u,
$$

which implies that $\sum_{i \in P} h_{i}(t) \cdot\left(x \circ \beta_{i}\right)(t) \in L^{1}\left[t_{2}, \infty\right)$. Therefore, for $i_{0} \in P$ for which $\left(A_{3}\right)$ holds, we have $x \circ \beta_{i_{0}} \in L^{1}\left[t_{2}, \infty\right)$. Then we conclude that $x \in L^{1}\left[t_{0}, \infty\right)$ by Property 3 . Hence $\sum_{i \in R} c_{i} \in B\left(\left[t_{0}, \infty\right)\right)$. $\left(H_{3}\right)$ and Property 4 imply that $w \in L^{1}\left[t_{1}, \infty\right)$. Since $r(t)$ is bounded, $b(t)=r(t) w(t)$ is also integrable in $\left[t_{1}, \infty\right)$. So we obtain that there exists a constant $M>0$ such that

$$
\int_{t_{1}}^{t} r(u) w(u) d u \leq M, \quad \forall t \geq t_{1}
$$

Let

$$
u(t)=w(t)+\int_{t_{1}}^{t} r(u) w(u) d u, \quad \forall t \geq t_{2}
$$

From (2.6), we have

$$
u^{\prime}(t)=z^{\prime}\left(t, t_{1}\right)+\sum_{i \in Q} \int_{\rho_{i}(t)}^{t} q_{i}(v) x\left(\gamma_{i}(v)\right) d v>0
$$

Then $u(t)$ is bounded and monotonous and $\lim _{t \rightarrow \infty} u(t)$ exists. We can suppose that $\lim _{t \rightarrow \infty} u(t)=\mu>0$ since $u(t)>x(t)>0$ and $u^{\prime}(t)>0$.

So there exists $t_{3} \geq t_{2}$ such that $u(t)>\mu-\varepsilon / 2, t \geq t_{3}$, for arbitrary $\varepsilon \in(0, \mu-M)$; by

$$
u(t)=w(t)+\int_{t_{3}}^{t} r(u) w(u) d u>\mu-\frac{\varepsilon}{2}
$$

we have

$$
\begin{aligned}
w(t) & >-\int_{t_{3}}^{t} r(u) w(u) d u+\mu-\frac{\varepsilon}{2} \\
& >\mu-\frac{1}{2}(\mu-M)-M \\
& =\frac{1}{2}(\mu-M) .
\end{aligned}
$$

This implies that $w(t) \notin L^{1}\left(\left[t_{1}, \infty\right)\right.$, which is a contradiction. 
Case $2\left(z^{\prime}\left(t, t_{1}\right)<0\right.$ for all $\left.t \geq t_{2}\right)$. Since $z^{\prime}\left(\cdot, t_{1}\right)$ is nonincreasing by (2.8), the inequality $z^{\prime}\left(t, t_{1}\right) \leq z^{\prime}\left(t_{2}, t_{1}\right)$ implies that $\lim _{t \rightarrow \infty} z\left(t, t_{1}\right)=-\infty$. Hence $z\left(\cdot, t_{1}\right) \notin B\left(\left[t_{1}, \infty\right)\right)$. We claim that $x \in B\left(\left[t_{0}, \infty\right)\right)$. On contrary, there exists $t_{3} \geq t_{2}$ such that $z\left(t_{3}, t_{1}\right)<0$ and $x\left(t_{3}\right)=\sup \{x(t): t \in$ $\left.\left[t_{0}, t_{3}\right)\right\}$. We get the following contradiction:

$$
\begin{aligned}
0 & >z\left(t_{3}, t_{1}\right)=w\left(t_{3}\right)+\int_{t_{1}}^{t_{3}} r(u) w(u) d u-\sum_{i \in Q} \int_{t_{1}}^{t_{3}} \int_{\rho_{i}(u)}^{u} q_{i}(v) x\left(\gamma_{i}(v)\right) d v d u \\
& \geq x\left(t_{3}\right)+x\left(t_{3}\right) \int_{t_{1}}^{t_{3}} r(u) d u-\sum_{i \in Q} \int_{t_{1}}^{t_{3}} \int_{\rho_{i}(u)}^{u} q_{i}(v) x\left(\gamma_{i}(v)\right) d v d u \\
& \geq x\left(t_{3}\right)\left[1+\int_{t_{1}}^{t_{3}} r(u) d u-\int_{t_{1}}^{t_{3}} \varphi(u) d u\right]>0
\end{aligned}
$$

since

$$
\int_{t_{1}}^{t_{3}} \varphi(u) d u<\int_{t_{1}}^{\infty} \varphi(u) d u<1
$$

Thus $\|x\|<\infty$. Accordingly, by (2.4) and (2.6), it follows that

$$
z\left(t, t_{1}\right) \geq w(t)+\int_{t_{1}}^{t} r(u) w(u) d u-\|x\| \int_{t_{1}}^{t} \varphi(u) d u \geq-\|x\| \int_{t_{1}}^{t} \varphi(u) d u>-\|x\|, \quad \forall t \geq t_{2} .
$$

Therefore, $\|x\| \geq\left\|z\left(\cdot, t_{1}\right)\right\|$ holds and we see that $z\left(\cdot, t_{1}\right) \in B\left(\left[t_{1}, \infty\right)\right)$, which is a contradiction. Therefore, we completed the proof by considering both possible cases.

Remark 2.3. When $r(t)=0$, and Theorem 2.2 reduces to Theorem 3.1 in [1]. So Theorem 2.2 extends and improves the corresponding results in $[1,4,10]$.

Theorem 2.4. Assume that $\left(H_{1}\right)-\left(H_{5}\right)$ hold and there exists a mapping $\psi: Q \rightarrow P$ which satisfies $\left(A_{1}\right)-\left(A_{3}\right)$. Furthermore, assume that $\sum_{i \in R} c_{i} \in B\left(\left[t_{0}, \infty\right)\right)$. If $\varphi \in L^{1}\left(\left[t_{0}, \infty\right)\right)$, then every solution $x$ of (1.2) is oscillatory or tends to zero asymptotically.

Proof. Suppose that $x$ is a nonoscillatory solution of (1.2). Without loss of generality, we assume that $x(t)>0$ for $t \geq t_{0}$. Therefore, we may assume existence of a constant $\varepsilon>0$ and $t_{1} \geq t_{0}$ such that (2.4) and $F(t) \leq \varepsilon$ hold for all $t \geq t_{1}$. Now, for $t \geq s \geq t_{1}$, set

$$
\begin{gathered}
W(t):=w(t)-F(t), \\
Z(t, s):=W(t)+\int_{s}^{t} r(u) w(u) d u-\sum_{i \in Q} \int_{s}^{t} \int_{\rho_{i}(u)}^{u} q_{i}(v) x\left(\gamma_{i}(v)\right) d v d u+\varepsilon,
\end{gathered}
$$


where $w(t)$ is defined on the interval $\left[t_{1}, \infty\right)$ as in (2.5). Then as in (2.8), we have

$$
Z^{\prime \prime}\left(t, t_{1}\right) \leq-\sum_{i \in P} h_{i}(t) x\left(\beta_{i}(t)\right) \leq 0, \quad \forall t \geq t_{1} .
$$

Thus there exists $t_{2} \geq t_{1}$ satisfying either $Z^{\prime}\left(t, t_{1}\right)>0$ or $Z^{\prime}\left(t, t_{1}\right)<0$ for all $t \geq t_{2}$.

We consider the following two possible cases.

Case $1\left(Z^{\prime}\left(t, t_{1}\right)>0\right.$ for all $\left.t \geq t_{2}\right)$. In this case, one can show that $w \in L^{1}\left(\left[t_{1}, \infty\right)\right)$ as shown in above proofs. Since $r(t)$ is bounded, $r(t) w(t)$ is also integrable in $\left[t_{1}, \infty\right)$. Let

$$
v(t)=W(t)+\int_{t_{1}}^{t} r(u) w(u) d u, \quad t \geq t_{2}
$$

By (2.19), we have

$$
v^{\prime}(t)=Z^{\prime}(t, s)+\sum_{i \in Q} \int_{\rho_{i}(t)}^{t} q_{i}(v) x\left(\gamma_{i}(v)\right) d v>0, \quad t \geq t_{2}
$$

then $v(t)$ is bounded and monotonous and $\lim _{t \rightarrow \infty} v(t)$ exists. By (2.21), we can obtain that $\lim _{t \rightarrow \infty} w(t)$ exists. Letting

$$
a(t)=w(t)+\int_{t_{1}}^{t} r(u) w(u) d u
$$

we can obtain that $\lim _{t \rightarrow \infty} a(t)$ exists. Suppose that $\lim _{t \rightarrow \infty} a(t)=\theta$, where $\theta \in[0, \infty)$. We claim $\theta=0$. Suppose that $\theta \in(0, \infty)$. By $r(t) w(t) \in L^{1}\left(\left[t_{1}, \infty\right)\right)$, we see that there exists $N>0$, such that

$$
\int_{t_{1}}^{t} r(u) w(u) d u \leq N
$$

Because $\lim _{t \rightarrow \infty} a(t)=\theta>0$, there exists $t_{3} \geq t_{2}$, such that $a(t)>\theta-(1 / 2) \epsilon, t \geq t_{3}$, for arbitrary $\epsilon \in(0, \theta-N)$. But by

$$
w(t)+\int_{t_{3}}^{t} r(u) w(u) d u>\theta-\frac{\epsilon}{2}
$$


we have

$$
\begin{aligned}
w(t) & >-\int_{t_{3}}^{t} r(u) w(u) d u+\theta-\frac{\epsilon}{2} \\
& >\theta-\frac{1}{2}(\theta-N)-N \\
& =\frac{1}{2}(\theta-N)
\end{aligned}
$$

this implies that $w(t) \notin L^{1}\left(\left[t_{2}, \infty\right)\right.$, which is a contradiction. Therefore, $\lim _{t \rightarrow \infty} a(t)=0$. Since $0<x(t)<a(t)$ for $t \geq t_{2}$, we have that $\lim _{t \rightarrow \infty} x(t)=0$.

Case $2\left(Z^{\prime}\left(t, t_{1}\right)<0\right.$ for all $\left.t \geq t_{2}\right)$. Then we have that $Z\left(\cdot, t_{1}\right) \notin B\left(\left[t_{1}, \infty\right)\right)$ by $(2.20)$. We claim that $x \in B\left(\left[t_{0}, \infty\right)\right)$. On contrary, there exists $t_{3} \geq t_{2}$ such that $z\left(t_{3}, t_{1}\right)<0$ and $x\left(t_{3}\right)=\sup \left\{x(t): t \in\left[t_{0}, t_{3}\right)\right\}$ hold and $\lim _{t \rightarrow \infty} Z\left(t, t_{1}\right)<0$.

Taking (2.4), (2.5), (2.18), and (2.19) into account, we get the following contradiction:

$$
\begin{aligned}
0 & >Z\left(t_{3}, t_{1}\right)=W\left(t_{3}\right)+\int_{t_{1}}^{t_{3}} r(u) w(u) d u-\sum_{i \in Q} \int_{t_{1}}^{t_{3}} \int_{\rho_{i}(u)}^{u} q_{i}(v) x\left(\gamma_{i}(v)\right) d v d u+\epsilon \\
& \geq x\left(t_{3}\right)\left[1+\int_{t_{1}}^{t_{3}} r(u) d u-\int_{t_{1}}^{t_{3}} \varphi(u) d u\right]>0 .
\end{aligned}
$$

Hence $\|x\|<\infty$. Accordingly, using (2.18), (2.19), and the fact that $w(t)>0$ on $\left[t_{2}, \infty\right)$, we have that

$$
\begin{aligned}
Z\left(t, t_{2}\right) & :=W(t)+\int_{t_{2}}^{t} r(u) w(u) d u-\sum_{i \in Q} \int_{S}^{t} \int_{\rho_{i}(u)}^{u} q_{i}(v) x\left(\gamma_{i}(v)\right) d v d u+\epsilon \\
& \geq w(t)+\int_{t_{2}}^{t} r(u) w(u) d u-\|x\| \int_{t_{2}}^{t} \varphi(u) d u \\
& \geq-\|x\|, \quad \forall t \geq t_{2} .
\end{aligned}
$$

Thus $\|x\| \geq\left\|Z\left(\cdot, t_{1}\right)\right\|$ and $Z\left(\cdot, t_{1}\right) \in B\left(\left[t_{1}, \infty\right)\right)$, which is a contradiction.

Therefore, we completed the proof by considering both possible cases.

Remark 2.5. If there exists $F \in C^{2}\left(\left[t_{0}, \infty\right), \mathbb{R}\right)$ such that $F^{\prime \prime}=f$ on $\left[t_{0}, \infty\right)$ and $l_{0}:=\lim _{t \rightarrow \infty} F(t)$ exists and is finite, then $G:=F-l_{0}$ on $\left[t_{0}, \infty\right)$ satisfies $\left(H_{5}\right)$. 
Corollary 2.6. If all conditions of Theorem 2.4 hold, then every nonoscillatory solution of (1.2) converges to zero at infinity.

Remark 2.7. When $r(t)=0$, Theorem 2.4 reduces to Theorem 3.3 in [1]. So Theorem 2.4 extends and improves the corresponding results in $[1,4,10]$.

\section{Examples}

In this section, we provide two examples to illustrate our main results.

Example 3.1. Consider the following equation:

$$
[x(t)+3 x(t-\pi)]^{\prime \prime}+\frac{1}{1+t^{2}}[x(t)+3 x(t-\pi)]^{\prime}+(t+1) x(t-2 \pi)-e^{-t-2 \pi} x(t-\pi)=0, \quad t \geq 1
$$

Here, we have

$$
\begin{gathered}
c_{1}(t)=3, \quad \alpha_{1}=t-\pi, \quad \beta_{1}=t-2 \pi, \quad \gamma_{1}=t-\pi, \\
p_{1}(t)=t+1, \quad q_{1}(t)=e^{-t-2 \pi}, \quad r(t)=\frac{1}{1+t^{2}} .
\end{gathered}
$$

Set the function $\psi$ with $\psi(1)=1$, then $\rho_{1}(t)=t-\pi$.

By simple calculation, we have

$$
\begin{gathered}
h_{1}(t)=t+1-e^{-t-\pi}, \\
\varphi(t)=e^{-t-\pi}-e^{-t-2 \pi}, \\
\liminf _{t \rightarrow \infty} h_{1}(t)=\infty \\
\int_{1}^{\infty} \varphi(u) d u=e^{-1-\pi}-e^{-1-2 \pi} .
\end{gathered}
$$

Therefore, according to Theorem 2.2, every solution $x$ of (3.1) is oscillatory. Clearly, the known results in [1-10] cannot be applied to (3.1).

Example 3.2. Consider the following equation:

$$
\begin{gathered}
{\left[x(t)+e^{-t} x\left(\frac{t}{2}\right)\right]^{\prime \prime}+\frac{1}{1+t^{2}}\left[x(t)+e^{-t} x\left(\frac{t}{2}\right)\right]^{\prime}+x\left(\frac{t}{2}-2 \pi\right)+x\left(\frac{t}{2}-\pi\right)} \\
-e^{-t} x\left(\frac{t}{2}-\frac{3 \pi}{2}\right)-\frac{3}{4} e^{-t} x\left(\frac{t}{2}-\pi\right)=e^{-t}-\frac{1}{t^{3}} \sin \frac{1}{t^{\prime}}, \quad t \geq 0 .
\end{gathered}
$$


Here, we have

$$
\begin{gathered}
R=\{1\}, \quad P=\{1,2\}, \quad Q=\{1,2\}, \\
c_{1}(t)=e^{-t}, \quad p_{1}(t)=p_{2}(t)=1, \quad q_{1}(t)=e^{-t}, \quad q_{2}(t)=-\frac{3}{4} e^{-t}, \\
\alpha_{1}(t)=\frac{t}{2}, \quad \beta_{1}(t)=\frac{t}{2}-2 \pi, \quad \beta_{2}(t)=\frac{t}{2}-\pi, \\
r_{1}(t)=\frac{t}{2}-\frac{3 \pi}{2}, \quad \gamma_{2}(t)=\frac{t}{2}-\pi, \\
f(t)=e^{-t}+\frac{1}{t^{3}} \sin \frac{1}{t^{\prime}}, \quad r(t)=\frac{1}{1+t^{2}} .
\end{gathered}
$$

Set the function $\psi: Q \rightarrow P$ with $\psi(i)=1$ for $i=1,2$; then $\rho_{1}(t)=t-\pi$ and $\rho_{2}(t)=t-2 \pi$.

By simple calculation, we have

$$
\begin{gathered}
F(t)=e^{-t}+t \sin \frac{1}{t}, \\
h_{1}(t)=1-e^{-t+\pi}-\frac{3}{4} e^{-t+2 \pi}, \quad h_{2}(t)=1, \\
\varphi(t)=\int_{t-\pi}^{t} e^{-v} d u+\frac{3}{4} \int_{t-2 \pi}^{t} e^{-v} d v, \\
\liminf _{t \rightarrow \infty} h_{2}(t)=1, \quad \int_{0}^{\infty} \varphi(u) d u=\frac{3}{4}\left(e^{2 \pi}-1\right)+e^{\pi}-1, \quad \lim _{t \rightarrow \infty} F(t)=1 .
\end{gathered}
$$

Therefore, according to Theorem 2.4 and Remark 2.5, every solution $x$ of (3.4) is oscillatory or tends to zero asymptotically. Clearly, the known results in [1-10] cannot be applied to (3.4).

\section{Acknowledgment}

The authors gratefully acknowledge the referee who pointed out the important reference [1] and gave some valuable suggestions which improved the results in this paper. Project supported by the National Natural Science Foundation of China (10771118), STPF of University in Shandong Province of China (J09LA04) and the Research Foundation of Qufu Normal University (XJ0620).

\section{References}

[1] B. Karpuz, J. V. Manojlović, Ö. Öcalan, and Y. Shoukaku, "Oscillation criteria for a class of secondorder neutral delay differential equations," Applied Mathematics and Computation, vol. 210, no. 2, pp. 303-312, 2009.

[2] X. Lin, "Oscillation of second-order nonlinear neutral differential equations," Journal of Mathematical Analysis and Applications, vol. 309, no. 2, pp. 442-452, 2005.

[3] Z. Liu and S. M. Kang, "Infinitely many nonoscillatory solutions for second order nonlinear neutral delay differential equations," Nonlinear Analysis, vol. 70, no. 12, pp. 4274-4293, 2009. 
[4] J. V. Manojlović, Y. Shoukaku, T. Tanigawa, and N. Yoshida, "Oscillation criteria for second order differential equations with positive and negative coefficients," Applied Mathematics and Computation, vol. 181, no. 2, pp. 853-863, 2006.

[5] S. Padhi, "Oscillation and asymptotic behaviour of solutions of second order homogeneous neutral differential equations with positive and negative coefficients," Functional Differential Equations, vol. 14, no. 2-4, pp. 363-371, 2007.

[6] N. Parhi and S. Chand, "Oscillation of second order neutral delay differential equations with positive and negative coefficients," The Journal of the Indian Mathematical Society. New Series, vol. 66, no. 1-4, pp. 227-235, 1999.

[7] R. N. Rath, N. Misra, and P. P. Mishra, "Non-oscillatory criteria for a class of second order non-linear forced neutral-delay differential equations," Mathematica Slovaca, vol. 59, no. 4, pp. 471-484, 2009.

[8] Y. Şahiner, "On oscillation of second order neutral type delay differential equations," Applied Mathematics and Computation, vol. 150, no. 3, pp. 697-706, 2004.

[9] W. Shi and P. Wang, "Oscillatory criteria of a class of second-order neutral functional differential equations," Applied Mathematics and Computation, vol. 146, no. 1, pp. 211-226, 2003.

[10] A. Weng and J. Sun, "Oscillation of second order delay differential equations," Applied Mathematics and Computation, vol. 198, no. 2, pp. 930-935, 2008. 


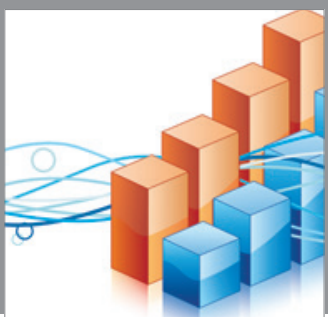

Advances in

Operations Research

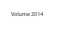

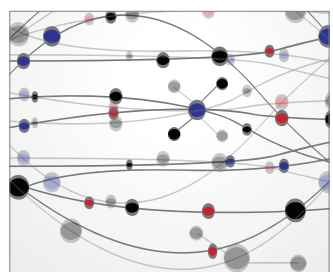

\section{The Scientific} World Journal
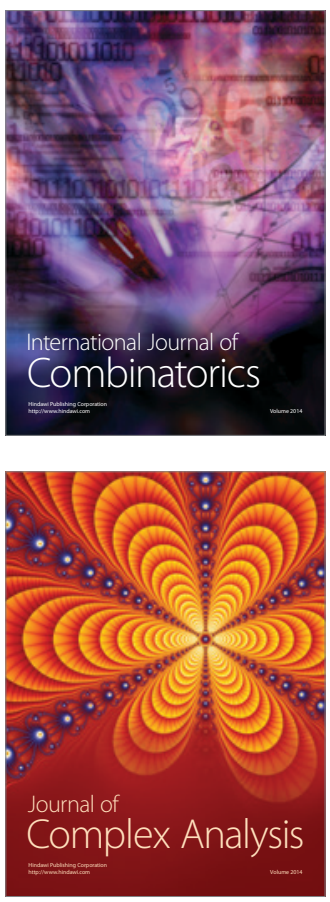

International Journal of

Mathematics and

Mathematical

Sciences
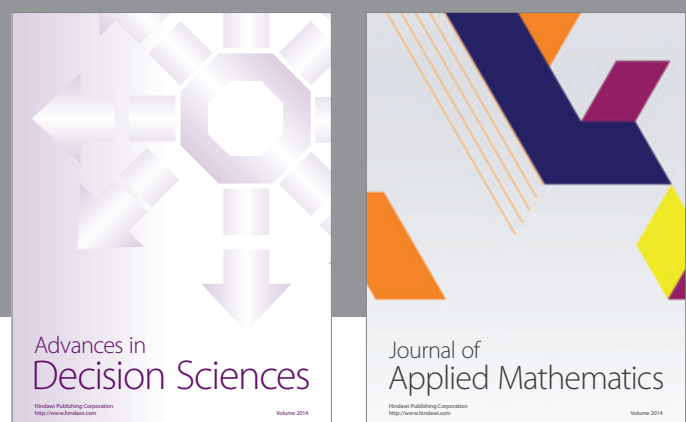

Journal of

Applied Mathematics
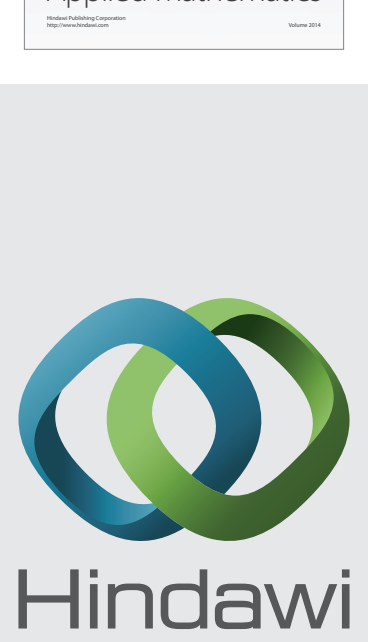

Submit your manuscripts at http://www.hindawi.com
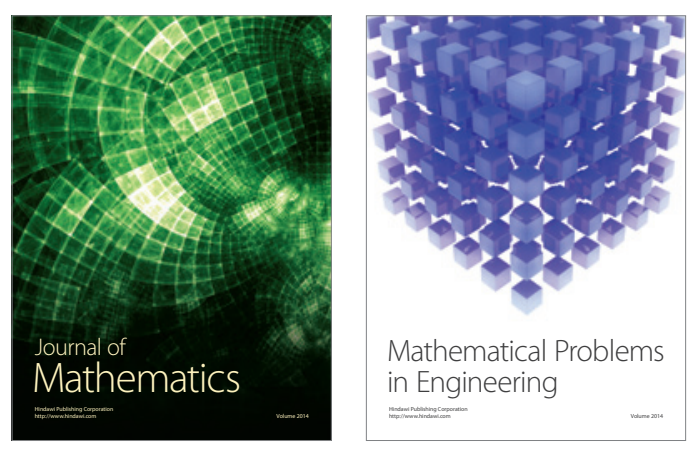

Mathematical Problems in Engineering
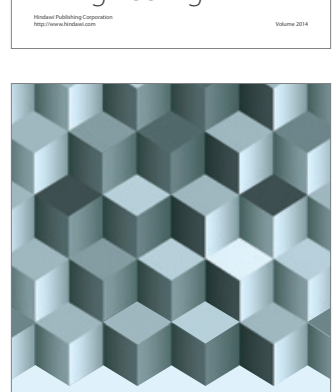

Journal of

Function Spaces
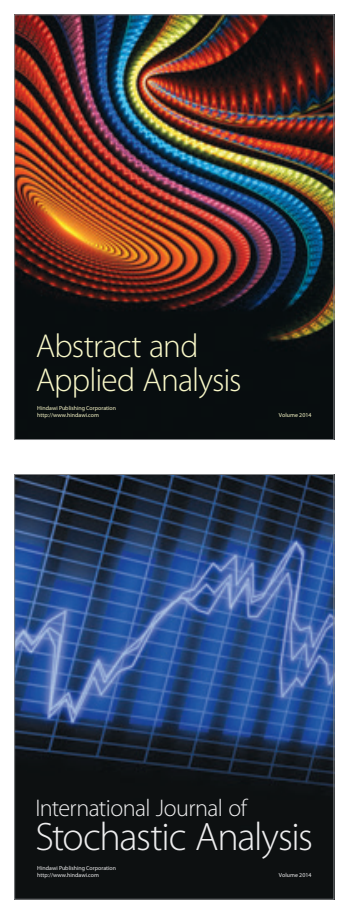

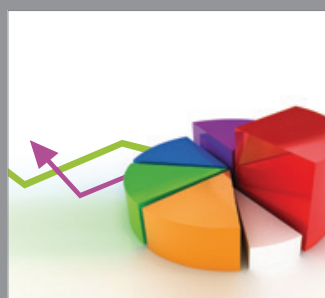

ournal of

Probability and Statistics

Promensencen
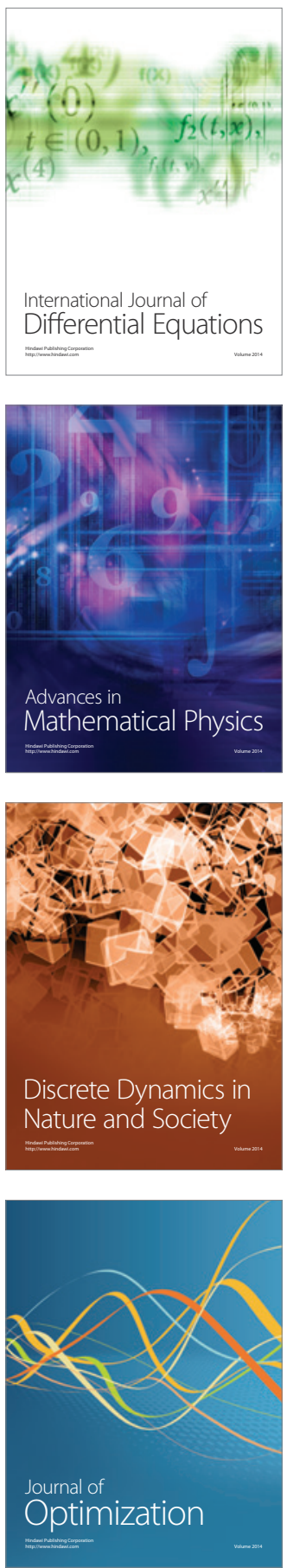